\title{
Analysis of the production process of the forked forging used in the excavator drive system in order to improve the currently implemented technology by the use of numerical modeling
} \author{
Dudkiewicz ${ }^{3}$ \\ ${ }^{1}$ Wroclaw University of Science and Technology, Wroclaw, Poland, \\ ${ }^{2}$ Kuznia Jawor S.A., Jawor, Poland, \\ ${ }^{3}$ Schraner Polska, Łeczyca, Poland
}

Marek Hawryluk ${ }^{1, *}$, Marcin Rychlik ${ }^{2}$, Jacek Ziemba ${ }^{1}$, Katarzyna Jasiak ${ }^{1}$, Filip Lewandowski ${ }^{1}$, Łukasz

\begin{abstract}
The study concerns a comprehensive analysis of a multistage hot-die forging on hammers, in order to produce a yoke-type forging, used as a component of excavator power transmission systems. The investigations were conducted with the aim to analyze and identify the sensitive areas in the process and then improve the currently implemented forging technology by using finite element (FE) simulation. QuantorForm (the developer of the QForm program) has developed a thermomechanical numerical model for the production of forked forging. The software Computer-Aided Three-Dimensional Interactive Application (CATIA) was used to develop and build Computer-Aided Design (CAD) models of forging tools. As a result of the numerical simulations, the plastic deformations and temperature distributions for the forgings and tools were obtained, and the force courses during the forging process were analyzed. The obtained results enabled a thorough analysis of the forging process, including identification of p otential forging d efects (laps) a s w ell as those tool a reas that a re the most loaded a nd exposed to damage. On this basis, changes were implemented in the production process, which allowed for the improvement of the currently implemented technology and obtaining the corrected forgings.
\end{abstract}

Keywords: closed die forging on hammers, numerical modeling, forked forging, forging defects

\section{Highlights}

- Use of FE modeling as an effective method for analyzing the industrial process.

- Analysis and detection of forging defects by special functions (by FE): folds, trapp, overlapping

- Use FE modeling for the insightful and comprehensive load analysis of forging tools

- Use of the results of numerical modeling to streamline and improve the forging technology.

- A practical solution does not require intervention and interruption of the production

*E-mail: marek.hawryluk@pwr.edu.pl process.

\section{Introduction}

Recently, there has been a large demand for components assigned for the agricultural and heavy industries. Consequently, we can observe a constant search for new technologies of producing components and subassemblies, including those of the yoke type, used for the essential elements of machines such as excavators, e.g., clutches or Cardan joints. Forgings of this type (often with masses of $>20 \mathrm{~kg}$ ) are used in excavator power transmission systems and constitute the key components of the joints. At present, in large lot productions, the multistep method of hot forging on hammers is applied, which involves semiopen forging and die forging, as well as additional "closing" operations 
(trimming, calibration, shot blasting, and so on). Such forgings also often constitute an important safety element, and hence, they must be characterized by high operational properties, dimensional and shape accuracy, as well as dimensional precision, absence of decarburization, and a proper fiber pattern [1].

The technology of hot forging on hammers to produce die forgings, which are components of joints (yoke type), still constitutes an unsolved problem as well as a big challenge. The reason is that, in the process of forging on hammers, an important role is played by not only the selection of appropriate technological process parameters but also the proper arrangement and forming of the forging material in the consecutive die impressions; this largely depends on the experience and skill of the operator, i.e., the forgeman [2]. The most important forging parameters affecting the quality of the forgings include the arrangement of the forging aggregate and other devices that are part of the production bay (forging cycle, speed), the shape and quality of the tools, the geometry of the charge and the preform, the thermal parameters of the preform and the tools, and the tribological conditions [3, 4]. Moreover, it is necessary at every stage of the entire technology chain to control the key process parameters and the selected physical quantities [5-7], as there is a potential risk of errors causing defects or a reduction in the quality of the final products, i.e., the forgings. It should also be taken into account that the wear of forging tools as a result of extreme operation conditions causes changes in the geometry of the produced item. An effect of this is that any surface tool defects are reflected in the forgings, thus influencing the functionality and quality of the finished product made of forging. During hot-die forging, the tools are exposed to very high periodical thermal loads ranging from $100{ }^{\circ} \mathrm{C}$ to even $900{ }^{\circ} \mathrm{C}$, as well as mechanical stresses reaching even $>1,200$ $\mathrm{MPa}$ [8]. The main and most frequent destructive mechanisms include the following [9, 10]: abrasive wear [11], mechanical cracking, plastic deformation [12], thermal oxidation [13, 14], and thermomechanical fatigue [15]. Forging defects may also be caused by other aspects, such as improper temperature of the charge material, the incorrect design and construction of the tool, or an underdeveloped technology. The diversity of factors determining the correctness of the forging, especially a multistage one, as well as the interaction between them, places them among those production processes that are the most difficult to analyze and realize. At present, in order to ensure a sufficient and, at the same time, proper production, the knowledge and experience of the forging technologists usually constitute the basis of manufacturing, whereby, increasingly often, are used tools supporting research works, such as computeraided design (CAD)/computer-aided engineering (CAE)/computer-aided manufacturing (CAM), as well as mathematical and numerical methods primarily based on the finite element method (FEM) [16-19], are applied for the analysis, design, and optimization of the manufacturing processes. Other advanced information technology (IT) and engineering tools are also used (e.g., noncontact scanning methods, thermovisual measurements) [1921]. It is still necessary to use advanced microstructural tests, defectoscopic tests, microhardness measurements, and the entire spectrum of research used in industrial companies. Especially, at present, the use of programs equipped with numerical packets installed on computer units with high computational powers enabling the numerical modeling of industrial processes is the best solution. Numerical modeling makes it possible to minimize the costs by way of performing a virtual experiment in place of the expensive and time-consuming experiments under industrial conditions. Appropriate experience in and knowledge of working with numerical calculation programs and consideration of the errors caused by the adopted simplifications in the FEM model make it a valuable tool in the analysis and improvement of current and new manufacturing technologies. Numerical modeling makes it possible to define the the flow of the material of the formed forgings and the process of cavity filling, the field of temperature distributions within the forgings and on the tools, as well as determination of the force parameters, stress and plastic deformation, and other important parameters [2224]. It needs to be highlighted that the time of the 
material forming during forging is $<0.2 \mathrm{~s}$, making it very difficult to track or conduct observations/thorough analysis of the manufacturing process in such a small time - in such a case, numerical modeling is irreplaceable $[25,26]$. In the available literature referring to numerical modeling of forging processes, we can find many studies discussing the application of the simulation results of determination of the optimal geometry and dimensions of the input material and the preform in order to detect forging defects, analyze their formation, and determine the key parameters of the process [27-30]. This is particularly warranted in the case of forged products having complicated shapes, such as forgings of yoke and turbine blades, gears, connecting rods, and so on [31-33], where on the basis of numerical simulation, we can specify the number of technological parameters, which allows more accurate and comprehensive analysis of the entire process [34-36]. For example, a previous study [37] has proposed an experimental numerical methodology for identifying the parameters of the constitutive laws applied for the hot forging processes realized in industrial presses. An another work [38] presents the numerical simulations referring to the whole production process, except for the machining treatment, of a front-toothed wheel forging for the rear gear of the motorcar gear box; similarly, another study [39] uses numerical modeling for the fast forging of railway axles made of $25 \mathrm{CrMo} 4$ steel by the application of Forge software (Transvalor, Sophia Antipolis cedex France), together with analysis of the evolution of the grain size during a multistage forging process at high speed. A 3D model of finite elements has also been used [40] to forecast the residual stresses and the deformations in the simulation of the water hardening of a large forged component made of highstrength steel. Hawryluk et al. [41] take advantage of numerical modeling to analyze and then develop an effective method for heating the forging tools.

Therefore, it is justifiable to apply numerical simulations for the investigation of industrial processes, such as spatial scanning, thermal imaging studies, and other research methods, supported and/or verified by other studies. These types of activities seem to be the right direction for the devel- opment of science, particulary in terms of searching for new solutions to problems on the border of the design of production processes and manufacturing technology and materials engineering. This approach enables a thorough and quick analysis of the problem and selected issues, as well as verification of the developed solutions under industrial conditions.

\section{Test subject and methodology}

The goal of the investigation is to conduct numerical simulations for a multioperational process of manufacturing of forked forging (used in the excavator power transmission system) through open forging and die forging on steam-air hammers. The constructed thermomechanical FEM model is applied for the analysis of the preset production process. Based on the obtained numerical simulation results and a complex analysis of the manufacturing process, the sensitive points in the process are identified and next possible corrections are introduced, thus improving the industrial forging process.

The item obtained in the analyzed production process is a yoke-type forging, commonly called "yoke". Forgings of this type are used for the essential components in machines, e.g., clutches or Cardan joints. Such a forging (with mass $>26 \mathrm{~kg}$ ), after mechanical treatment and other procedures, is used in power transmission systems of excavators and constitutes the key element of power transmission system joints. Figure 1A shows an image of a hot forging right after the forging process, assigned for hot trimming, Figure 1B presents a photograph of a cooling forging after the flash has been cut, and in Figure 1C, we can see a CAD model of a forging after mechanical treatment.

According to the forging classification, the socalled "yoke" belongs to the group M1 (material difficulty), S2 (shape compactness), F1 (accuracy class) and is made with the accuracy according to European Standard (EN-10243-1:1999). The input material is a bar made of C45E steel with the following profile: diameter $\mathrm{d} \varnothing=120$ and the length $=314 \mathrm{~mm}$. The process of producing such an element is complex and runs through a dozen or a 

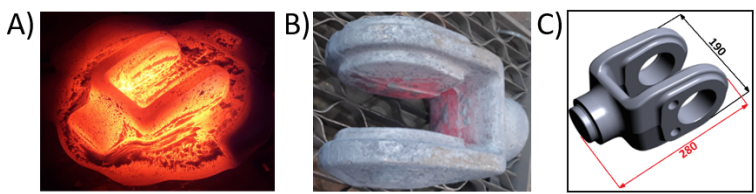

Fig. 1. View of (A) a 'hot' forging with the flash after the forging process, (B) a cooling forging after trimming, and (C) a CAD model of a forging after mechanical treatment.

lot of procedures, as well as forging operations on two aggregates, which makes it relatively difficult to properly perform.

For a comprehensive analysis of the manufacturing process of a forked forging (yoke-type element), we have performed an in-depth analysis of the forging process using, among others, a thermovision camera FLIR 440 and a highspeed Casio camera (Exilim ProEX-F), to the forging flaws/defects, and macroscopic research of the tools using a Canon EOS photo camera. Furthermore, spatial scanning (measuring arm: ROMER Absolute Arm 7520si with an RS4 scanner) of a ready forging obtained using the current technology was performed. Based on the technical documentation, CAD models of the ready forging and the tools were constructed using the ComputerAided Three-Dimensional Interactive Application (CATIA, v5) CAD program. On the basis of the above information, numerical models were elaborated and computer simulations of the hot forging process were performed using the computation packet QForm 9, developed by QUANTORform (107 Oxford Road, Oxford, OX4 2ER, United Kingdom) to determine the main parameters and factors, as well as physical quantities, in addition to identifying the biggest problems. In order to verify the improvements made on the basis of numerical simulations, the geometry of the forging was measured in relation to the forging before the changes.

\section{Analysis of industrial forging process}

After being cut, the charge material is transported into an induction heater, where it is heated to about $1,170-1,230{ }^{\circ} \mathrm{C}$. Next, it is open die forged on an MPM6300 hammer in six blows: upsetting $(2 \times)$, flattening $(2 \times)$, and leveling $(2 \times)$. In turn, the die forging process takes place on an MPM16000B hammer in about 7-8 aggregate blows, which include roughing $(4 \times)$ and finishing forging $(3 \times)$ (Figure $2 A$ and $B$ ).

After the forging, hot trimming of the flashes takes place (Figure 2C), right after which, on the same forging press, hot calibration is carried out (Figure 2D). Figure 3 shows the other additional stages and aspects of the forging process, which, based on a preliminary analysis of the technology, can have an important effect on the correctness of the whole technology. Figure $3 \mathrm{~A}$ presents the transport of the forging from the open die forging operation to the die forging step carried out on an MPM 16000B hammer, for which the average time is $12-14 \mathrm{~s}$. Additionally, the time of placing the preform into the preliminary die impression is strongly dependent on the forgemen-operators and equals about $3-5 \mathrm{~s}$ from the first blow.

In the analyzed process, before being mounted in the upper and lower tables of the hammer, the dies made of WNLV steel (1.2714/55NiCrMoV7) are heated on gas burners to a temperature of 200 ${ }^{\circ} \mathrm{C}$. The mass of both dies is $1,300 \mathrm{~kg}$ (Figure 3B). During the forging process, the tools are periodically loaded mechanically and thermally, and such extreme working conditions can cause their premature wear or damage. During the process, before the blow, the operators spread the tools with sawdust, which burns and thus produces air cushions facilitating the removal of the forging from the die. After the end of the process, and after the last blow in the finishing operation, the tools are lubricated with a very large amount of a graphite-and-water mixture. After the hot calibration, the forgings are dropped into a container, which, in the case of heavy and hot forgings, can cause cuts and bruises (Figure 3C).

\section{FEM modeling}

Numerical simulations of the multioperation process of hot forging on hammers were performed using the latestversion of the QForm 9 software. The preliminary calculations carried out to determine the modeling parameters were conducted on 

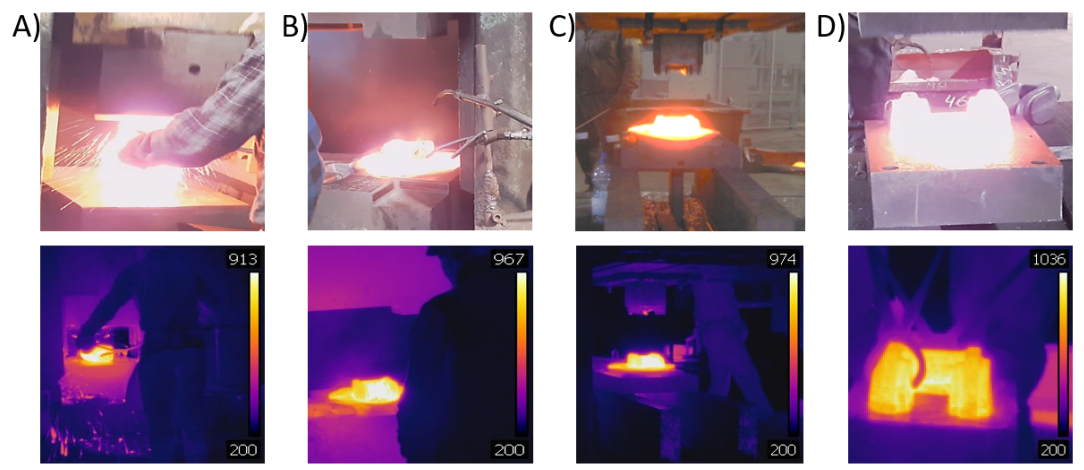

Fig. 2. Images of the consecutive operations of forming a yoke-type forging and the corresponding analysis of the temperature distributions made with a thermovision camera: (A) upsetting during open die forging; (B) finishing forging; (C) hot trimming; and (D) calibration.
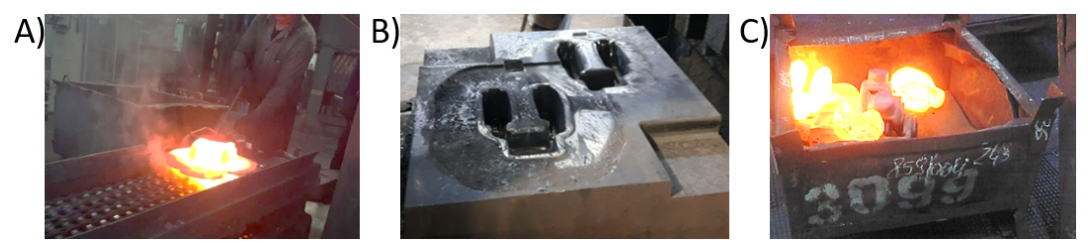

Fig. 3. Other selected stages of the process which can affect the correctness of the whole technology: (A) transport of the forging from open forging to die forging; (B) lower die for roughening and finishing forging during a maintenance shutdown; and (C) container with hot forgings after hot calibration.

simplified mechanical models with rigid tools, and then, the calculation model was expanded. All the simulations were conducted for 3D models of the thermomechanical model with deformable tools (forging dies).

In order to properly perform the simulation, it is necessary to recreate the parameters of the given process. The material used for the charge $(\mathrm{C} 45 \mathrm{E}$ steel) was selected from the program's material database, and for the dies, steel for hot impact operation was chosen, i.e., $55 \mathrm{NiCrMoV7}$, according to the standard by Deutsches Institut für Normung (DIN: 1.1713) with Young's modulus of about 200 GPa. In the database of the QForm software, for the material on forgings, the flow curves are in the form of charts of true stress dependence: strains, temperatures, and strain rates. In the process, the dies are preheated on gas burners to $200^{\circ} \mathrm{C}$, and next, they are mounted on the aggregate and heated again until they reach the required forging temperature. In the real process, the material input to the first operation is heated to range: $1,180-1,220^{\circ} \mathrm{C}$ (assumed to be $1,200^{\circ} \mathrm{C}$ in the model $\mathrm{FE}$ modeling) and then cooled in air during each blow for about $2 \mathrm{~s}$ and between the operations for $3 \mathrm{~s}$. For the modeling, the Levanov friction model was assumed, with the coefficient of 0.4 (in the industrial process, graphite with water is used). For the elongation operation, a manipulator holding the material of a low-pressure force was applied, which simulated the forge tongs. As the forging aggregate, $3 t$ and $5 t$ hammers were selected, with the characteristics assumed from the program's database. The elaborated CAD models of both the dies and the input material have been digitized. In the modeling, tetrahedral elements of the TET4 type (tetrahedra) were used, assuming the ratio of the largest-to-the-smallest element equal to 8.0. The input material of forging included 4,366 and 12,884 (number of elements before and after the process, respectively) during the open die forging operations, 22,344 and 211,687 elements during roughing, and 222,144 and 316,086 elements during finishing. The dies have been assumed to be deformable, and the upper die was set in accor- 
dance with the specification of both forging aggregates (hammers). The heat transfer coefficients between the input material and the dies' material have been assumed as $28 \mathrm{~kW} / \mathrm{m}^{2} \mathrm{~K}$ and $0.33 \mathrm{~kW} / \mathrm{m}^{2} \mathrm{~K}$. The plastic deformation coefficient was assumed as 0.98 , which means that $98 \%$ of the plastic deformation work takes place on heating.

\section{Results and discussion}

The investigation was divided into two steps. The first one concerned the shaping of the forging, and the second one involved the analysis of the forging forces and the dies.

\subsection{Quality analysis of the forgings}

Figure 4 shows the results of the analysis of the dimensional changes of the 100th forging obtained in the currently used technology, related to the CAD model - the nominal forging. Similar results were obtained for consecutive forgings collected every 100 times, up to 1,200 (average die durability), with a tendency to enlarge the dimensions. They were then scanned using the scanner.
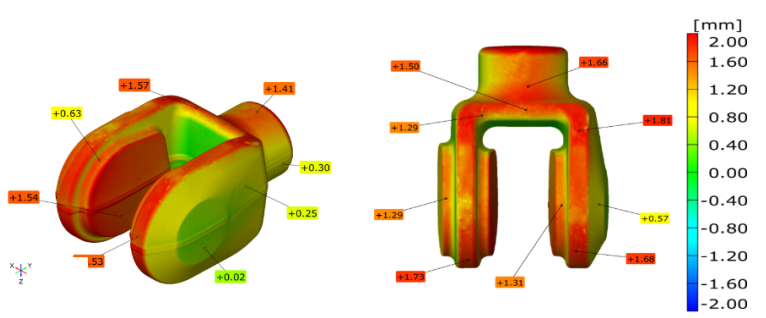

Fig. 4. 3D scanning analysis of the geometrical changes of forgings in the actual forging process.

Based on the analysis of the presented results (Figure 4), it can be seen that the dimensions in the selected areas show large differences and discrepancies. For this type of relatively heavy forgings, yet assigned for the essential components in power transmission systems (for surfaces to be machined after forging), dimensional tolerances should be within the following range: the bottom: $-0.1 \mathrm{~mm}$, and the top: $+1.2 \mathrm{~mm}$. Hence, based on the obtained scanning results, we can state that it is necessary to introduce slight changes into the technology, es- pecially in the geometry of the impressions of the die-forging tools.

\subsection{Roughing and finishing forging}

In the first place, numerical modeling of the currently realized technology was performed, in order to analyze the manner of impression filling in the particular operations (Figure 5). During the analysis of the industrial forging process, it was found that it is very important to make a correct preform during the forging on a $3 \mathrm{t}$ hammer, in addition to positioning it well on the die, because, otherwise, underfills or laps may be formed during the forging on a $5 t$ hammer. The main task set to the roughing procedure is to unload the finishing impression. If a larger part of the preform is formed in the preceding operation, the durability of the main impression increases.
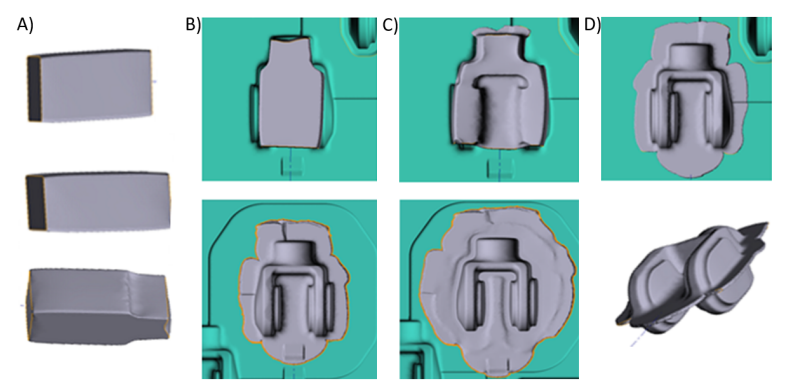

Fig. 5. View of the impression's filling: (A) open forging operations; (B) forging in the roughing pass (placing the preform, after the second blow, and after the last blow); (C) forging in the finishing impression (after the first and the last blows); and (D) model of a ready forging with flash.

The last operation finalizing the making of the forging is finishing forging (Figure 5C), which aims to give it the final shape, especially for achieving the smallest radii and flatter and sharper surfaces (Figure 5D). By analysis of the obtained results (Figure 5), we can state, based on the numerical simulations (impression filling), that the presently applied technology was designed correctly. However, analyzing the manner of flow of the shaped material and filling of the impressions, one can conclude that a lot depends on the manual skills of the operators during the industrial process, as a slight shift of the preform in the impression 
or its quite improper reshaping during open forging can be the cause of many defects and errors in the forgings. Therefore, the tools, both during open forging and die forging, should be properly worked out geometrically, so that the process is repeatable and stable. For example, it is possible to carry out the replacement from the roughing pass into the finishing impression with a simultaneous rotation, which corrects the filling on both sides of the forging. Additionally, based on the observations, the industrial process consisted of 10 blows, despite the fact that, according to the information on the operation sheet, it should have been realized in three blows.

\subsection{Distribution of plastic deformations}

Figure 6 shows the plastic deformation distributions for open die forging, as well as for roughing and finishing forging.

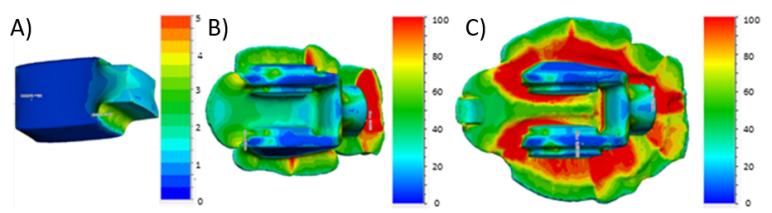

Fig. 6. Distributions of plastic deformations after forging: (A) after flattening of the tip and leveling; (B) after roughing; and (C) after finishing forging.

As we can see in Figure 6, the preform material was formed in such a way that it would flatten one of the tips, which next would make it possible to shift the mass and ensure proper filling of the roughing pass. The largest plastic deformations for the preform are localized in the flattened tip (Figure 6A). Figure 6, panels $\mathrm{B}$ and $\mathrm{C}$, presents the plastic deformation distributions for the preforms (after the last blow) in the operations of roughing and finishing forging. We can notice that the largest deformations are localized in the flash for the forging after roughing, in the vicinity of the flash by the shank, whereas for the forging after finishing forging, the largest deformations are located in the flash in the vicinity of the arms. Very large plastic deformations as a result of the conversion of the deformation work into heat, as well as the friction result- ing from it, will generate a lot of heat, which will be transferred to the tools. On the other hand, much cooler tools during forging process cool down the forging on the contact surfaces between them.

\subsection{Distributions of temperatures, means, and reduced stresses in the dies}

In addition to the analysis of the forging process, an analysis of the distribution of temperatures, as well as the reduced and mean stresses, on the dies was performed in order to identify the areas that are most susceptible to crack and abrasion. The results of numerical simulations for the key parameters related to tool durability are presented in Figure $7 \mathrm{~A}-\mathrm{C}$ for the preliminary die impression and Figure $7 \mathrm{D}$ and $\mathrm{E}$ for the finishing impression. On the roughing pass,, in the areas where the external flash is formed and inside, beyond the pass, due to the fact that the roughing pass was conducted without a groove, in order to hinder the material flow and ensure filling of the impression, a clear temperature increase is visible, reaching even levels $>400{ }^{\circ} \mathrm{C}$ (Figure 7A). In turn, on the finishing impression, the temperature distribution is more uniform and equals about $200{ }^{\circ} \mathrm{C}$. In the case of the mean and reduced stress distributions, the preliminary die impressions are less loaded, being slightly more shallow; the observed reduced stresses oscillated between $250 \mathrm{MPa}$ and $400 \mathrm{MPa}$ (Figure 7B), whereas the mean stresses varied from $-150 \mathrm{MPa}$ to $200 \mathrm{MPa}$ (Figure 7C). The most loaded impression is the finishing one, where the reduced stresses are in the range of 1,000-1,200 MPa (Figure 7F) and the mean stresses range from -400 MPa to 600 $\mathrm{MPa}$, especially on the radii in the deepest areas of the impressions (Figure 7E).

The high stress values and large friction paths can cause thermomechanical fatigue and abrasive wear, as well as premature tool decommissioning, which were observed during industrial forging, mainly in the rough pass and finish impression (Figure 3B). 


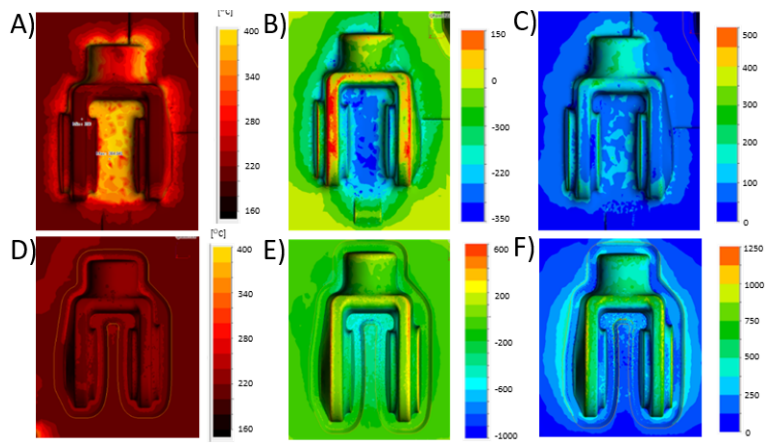

Fig. 7. Numerical simulation results: (A) temperature distributions; (B) mean stress distributions; (C) reduced stress distributions on lower dies during roughing; and (D-F) parameters analyzed for finishing forging.

\subsection{Identification and analysis of forging defects}

The greatest hazards during forging of the analyzed samples are forging flaws and defects. In the analyzed process, the biggest problem is a properly made preform during open forging on a $3 \mathrm{t}$ hammer, which depends on the skill of the forgemanoperator, as well as a correctly placed preform in the roughing pass and the finishing impression during die forging on a $5 \mathrm{t}$ hammer. The most important are the underfills and laps (Figure 8A and B), as well as cuts of the material (Figure $8 \mathrm{C}$ ).
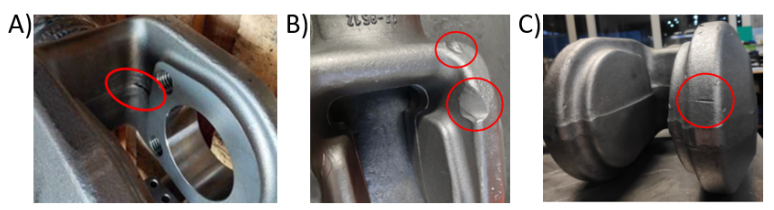

Fig. 8. Defects on the forgings observed after the forging process: (A) laps revealed after mechanical treatment between the arms in the parting plane; (B) underfills observed after shoot blasting; and (C) cuts and wraps after trimming and blasting.

The main problem is with underfills, which appear during the flow; a part of the material remains between the dies, forming a wrap or a lap (Figure $8 \mathrm{C}$ ), which, in successive blows, is pressed into the flash. Defects of this type were observed during the analyzed industrial process, particulary in the matter of improperly followed technology, e.g., in- correct placing of the preform or wrong length of the preform (caused by an incorrect preforging). In turn, flaws in the form of a lap in the parting plane, revealed in the picture of the material during mechanical treatment (Figure 8A), after the analysis of the numerical simulation results as well as observations, are caused by the material being wrapped on the finishing impression. The cause of the defects - cuts shown in Figure 8C - is probably the hot forgings bumping into each other right after the forging process, as they are dropped into the container (Figure 3C).

In turn, for the identification of the other defects, namely, laps and underfills, numerical simulations were applied. The use of special functions (e.g., folds) in the program makes it possible to simulate different variants of arrangement and detect those areas of the formed material that are mostly exposed to defects (Figure 9).
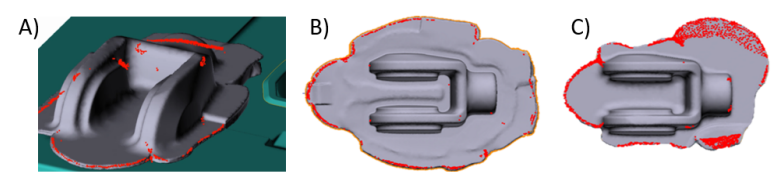

Fig. 9. The most common forging defects and exemplary results of forging defect detection obtained from FEM, using the "folds" function (laps): (A) visible laps on the arms and in the shank during preliminary die forging; (B) wrong arrangement in the die (too high) - laps on the arms, (C) too strong flattening of the tip (laps on the corners and in the mandrel). FEM, finite element method.

In order to identify the underfilling shown in Figure $8 \mathrm{~B}$ (photo of forging after shoot peening), a numerical simulation was performed using a special "trap" function applied for the detection of the so-called air pockets. During the process analysis, very intensive lubrication was observed, which, in combination with insufficiently heated tools, could have caused incomplete vaporization of the water from the lubricating mixture, which remained in the lowest areas of the impression. Figure 10A shows the simulation results for the tool-forging contact along with the activated 'trap' function at the end of the forging operation, confirming the 
presence of a defect in the form of an underfill in the initial part of the arms.

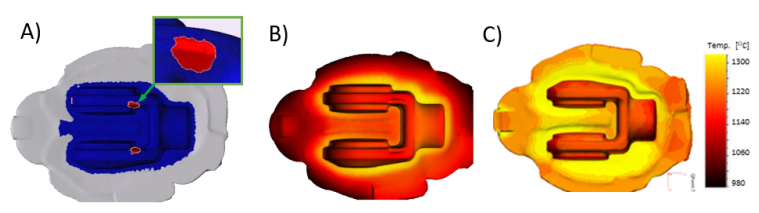

Fig. 10. Filling of the impression of a yoke forging made in a prolonged working cycle: (A) results presenting the tool-forging contact, pointing to an underfill at the beginning of the arms; (B) temperature distributions for a cooled forging during an increased number of blows; (C) temperature distributions for a forging made according to the improved technology.

Also, a significant problem during production are the habits acquired by the operators of doubleaction hammers, which perform blows with a lower pressure force (thus maintaining the air access to the cylinder partially closed). In this case, instead of applying the assumed 4-5 blows of roughing and three blows of finishing forging, the cycle is prolonged (in extreme cases, even two times). Beside lowering the production efficiency, the forging time has a significant effect on the material temperature, especially on the external surface of the forging. In turn, Figure 10B presents the temperatures on the surface of the forging with an increased number of blows, which was correlated with the temperature distributions for the forging made according to the current technology (Figure 10C). Analyzing the results obtained from FEM, we can state that they confirm the possibility of the occurrence of lubricant remains in the lower areas of the lower tool during the industrial process, which form an additional volume and cause underfilling in this area of the forging. In turn, in the analysis of the temperature distribution, we can see that the temperature values have lowered from $1,160{ }^{\circ} \mathrm{C}$ to $980{ }^{\circ} \mathrm{C}$ on the surface of the arms and from $1,300{ }^{\circ} \mathrm{C}$ to 1,200 ${ }^{\circ} \mathrm{C}$ in the area of the flash. The tendency to lengthen the process indicates significant heat losses, which affect the product quality and the durability of the forging tools. The analysis of the forging forces in such a case showed that the force in the last blow during the finishing operation increased from
$26,000 \mathrm{kN}$ to $34,000 \mathrm{kN}$, which is presented during the analysis of the improved forging technology (Figure 11).

\subsection{Changes and improvements to the current technology}

The identified defects and problems encountered in the process, verified through numerical modeling, caused the necessity to introduce changes into the technology. It was decided to establish the optimal number of blows in the roughing operation as four and in the finishing operation as two. Additionally, in the lower die, the parting plane was lowered, as the track after the trimmed flash has to be parallel to the parting plane. The radius of the exit from the bridge to the impression was possibly small, thus creating a good base for the trimming operation on the punching die, which also played the role of a brake, counteracting the material outflow beyond the impression. Similarly, the roughing pass was reconstructed in a way that would facilitate its shift as well as proper filling, especially in the areas of rapid changes in the cross section or sharp radii. In the analyzed case, an impression reduced by width and length was applied, in order to ensure reliable leveling in the following procedure, without the risk of underfilling of the final product. An exception is the area most difficult to fill, i.e., the arms of the forging, which were elevated due a deep impression with a small inclination angle. In this operation, large radii of the exit onto the die's parting plane were applied, without bridges or magazines for the flash. In order to make it easier to obtain the required height without blocking the dies with the flash, magazines were used. Additionally, to control the material flow out of the impression, brakes were applied for the flash flowing through the bridge into the magazine.

Moreover, the results of the conducted analyses indicate the need to ensure more optimal tribological parameters during forging in industrial conditions, as the thermovision measurements showed a slight overheating of the tools in the process. On the other hand, numerical simulations have shown that in the case of an extended forging cycle or an extended time for setting the forging after transport 
from open forging, the temperature of the forging may, in extreme cases, differ by $>100{ }^{\circ} \mathrm{C}$, which may translate into premature wear of the dies. Providing better tribological conditions requires a thorough analysis of the amount of lubricant and the method of its application, as well as the repeatability and stability of the entire forging process. Moreover, the lubrication conditions were altered through slight dilution of the lubricant and reduced lubricant doses. Therefore, in the industrial forging process, intensive research and tests have been carried out using a fully automatic cooling and lubricating device developed by the authors, which has been successfully used during forging on presses [42-44], where there are much lower mechanical drag values, than when hammering is the case.

Next, more simulations were conducted, making it possible to analyze the introduced changes in order to implement them into the industrial process.

\section{Verification of results}

To verify the results, taking into account the information obtained from the FEM on the reconstruction of geometry, fingerprint sensor, and the tribological conditions, we carried out a new forging process.

\subsection{Forging force courses}

The several performed simulation variants made it possible to determine the optimal number of blows during the roughing operation $(4 \times)$ and the finishing forging operation $(2 \times)$ in order to ensure proper filling of the impressions and distributions of temperature in the forging (no cooling and lower forging forces). Figure 11 presents the forging forces as a function of the stroke (closing the dies: upper with lower, for a given flash thickness).

Analyzing the forging force courses, we can notice that the biggest forces are observed during finishing forging and roughing (last blow) and they are $>20,000 \mathrm{kN}$. In turn, for the preliminary die forging (first blows) and open die forging, the forces are much lower. High values of forces during the forging - asseen from the results of the numerical analyses for the loads (high pressures and temperatures) - of the dies and large friction tracks can cause cracking and also abrasive wear. In the anlaysis, one should also consider the cooling of the preform after the open die forging during the transport on the chain conveyor (Figure 3A) to the die forging MPM16000B hammer (for about $12 \mathrm{~s}$ ) as well as a large number of blows resulting from the habits of the operators. Too long a period of transport can increase deformation resistance of the forging during the forging process, which may also result in an increase of forces (curve with red markers) by about $15 \%$ and consequently cause cracking of the dies in the areas of their heaviest cross sections. This has also been demonstrated by the results of simulations of an excessive number of blows, which causes cooling of the forging (Figure 10B).

\subsection{Temperature distributions of the forg- ings during subsequent operations}

Figure 12 shows the temperature field distributions for subsequent multistage forging operations after modifications and improvements in the technology implemented so far.

During initial forging (Figure 12A and B), the most heated part of the shaped material is a thin flash, on which the temperature rises very quickly. This is due to the small thickness compared to the entire forging. Similarly, in the finishing blank, the thinnest area of the forging bridge is heated the most (Figure 12C and D). However, these areas cool just as quickly as opposed to the clustered thick part. At the same time, owing to cooler dies on the contact surface of the tool with the shaped forging, the temperature is much lower (even 150$200^{\circ} \mathrm{C}$ during die forging). Provision of optimal temperature conditions related to the correct course of the process and lubrication, i.e., tribological conditions, is crucial for the quality of forgings and tool durability.

\subsection{Quality and dimensional accuracy of forgings}

Similarly to the originally realized process, for the geometry change examinations, the 100th as well as every next 100th forging were scanned. Using the PolyWorks program, the dimensional devi- 


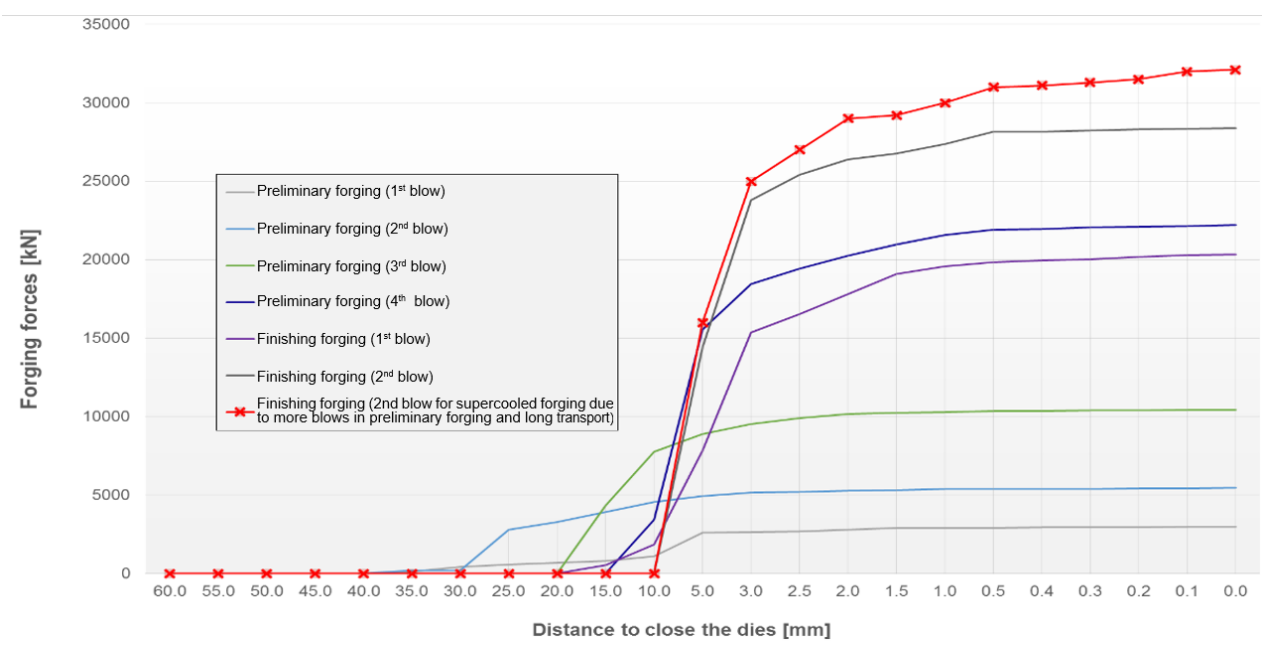

Fig. 11. Forging force courses for particular operations in the function of distance to close of dies.
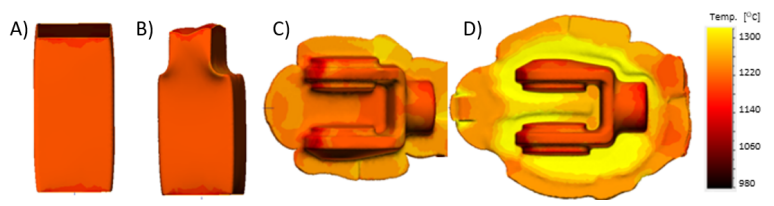

Fig. 12. Temperature distribution on the material in initial forging: (A) after upsetting; (B) after flattening the end and leveling; (C) after initial forging (after four strokes); and (D) after finishing forging (after two strokes).

ations of the ready 1,000 th forging in the nominal dimensions were demonstrated. On this basis, we can conclude that both the design of the tools and their construction were performed properly, and the forgings are within the tolerance scope.

Based on the comparison of the scans before (Figure 4) and after (Figure 13) changes, it can be stated that the improvements made to industrial forging resulted in more accurate products, i.e., forgings with a narrowed tolerance field for dimensional tolerance, which justifies the use of FE modeling for process optimization forging.

\section{Summary and conclusions}

The study presents the results of numerical simulation of the manufacturing process of forked forging, the so-called "yoke", which made it possible to obtain a lot of important information difficult

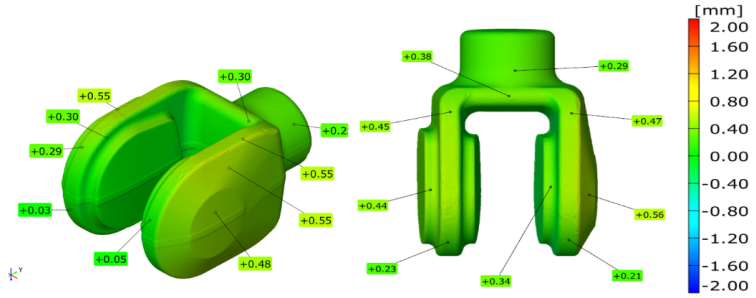

Fig. 13. Comparison of the produced 1,000th forgings after improvements and changes resulting from FEM. FEM, finite element method.

to obtain during the analysis of industrial forging, e.g., filling of blanks, as well as detection of forging defects, temperature field distributions in forgings and dies, and distributions of stresses and forging forces. The performed analysis has demonstrated that the technology applied so far was designed properly, yet it requires certain improvements in respect of technological parameters (lubrication and heating of the dies, as well as setting of the optimal number of blows of the MPM16000B hammer).

The biggest problem is related to the open die forging, and to a lesser degree, with the correctness of the placement of the preform during die forging. In both cases, a key role is played by the experience of the forgeman-operator. Therefore, it is necessary to modify the geometry of the die forging tool impressions in order to ensure stability and repeatability of the process.

By taking into account the FEM results and the 
subsequent introduction of corrections (mainly the distribution of the batch material and temperature parameters) during forging, a high dimensional accuracy of the finished forging was obtained (verified on the basis of measurements using the 3D scanning method), thus confirming the correctness of the assumptions and simplifications made during numerical simulations. The presented results can be used for the optimization of selected parameters of similar forging processes, as well as the shape of the tools, in the context of the quality of the forging and the durability of the tools.

\section{Acknowledgements}

The research has been financed (NCBR, Poland) within the project POIR.01.01.01-00-0047/17-00.

\section{References}

[1] Semiatin SL. Metalworking: Bulk Forming, ASM Handbook; 2009.

[2] Hawryluk M, Rychlik M., Krawczyk J., Gronostajski, Z. Nowak B., Jabłoński P. Analysis of the forging process of fork type forging used in the excavator's drive system using the results of numerical simulation. HutnikWiadomości Hutnicze. 2018;85(8):251-5.

[3] Vazquez V, Altan T. New concepts in die design - physical and computer modeling applications. J Mater Process Technol. 2000;98(2):212-23.

[4] Gronostajski Z, Hawryluk M. The main aspects of precision forging. Arch Civil Mech Eng. 2008;8(2):39-57.

[5] ISO GPS 10360-4:2000. Geometrical Product Specification - Acceptances and Reverification Tests for Coordinate Measuring Machine- Part 5: CMMs used in Scanning Measuring Modes; 2002.

[6] Mathia TG, Pawlus P. Recent trends in surface metrology. Wear. 2012;282:495-1.

[7] Hawryluk M, Ziemba J. Application of the 3D reverse scanning method in the analysis of tool wear and forging defects. Measurement. 2018;128:204-13.

[8] Taylan A, Gracious N, Gangshu S. Cold and hot forging fundamentals and application. ASM Int. ASM Metals Handb. 2005;14:337-8.

[9] Gronostajski Z, Kaszuba M, Polak S, Zwierzchowski M, Niechajowicz A, Hawryluk M. The failure mechanisms of hot forging dies. Mater Sci Eng. 2016;657:147-60.

[10] Lavtar L, Muhic T, Kugler G, Tercelj M. Analysis of the main types of damage on a pair of industrial dies for hot forging carsteering mechanisms. Eng Fail Anal. 2011;18(4):1143-52.

[11] Archard J. Contact and rubbing of flat surfaces. J Appl Phys. 1953;24(8):981-8.

[12] Kim DH, Lee HC, Kim BM, Kim KH. Estimation of die service life against plastic deformation and wear during hot forging processes. J Mater Process Technol.
2005;166(3):372-80.

[13] Choi C, Groseclose A, AltanT. Estimation of plastic deformation and abrasive wear in warm forging dies. $\mathbf{J}$ Mater Process Technol. 2012;212(8):1742-52.

[14] Starlinga CM, Brancob JR. Thermal fatigue of hot work tool steel with hard coatings. Thin Solid Films. 1997;308(309):436-42.

[15] Berti GA, Monti M. Thermo-mechanical fatigue life assessment of hot forging die steel. Fatigue Fract Eng Mater Struct. 2005;28(11):1025-34.

[16] Furrer DU, Semiatin SL. ASM Handbook, Volume 22B - Metals Process Simulation; 2010.

[17] Bašić H, Duharkić M, Burak S. Numerical simulation of hot forging process in production of axisymmetric automobile parts. Period Eng Nat Sci. 2019;7(4):1572-81.

[18] Su G, Zhang A. Three-dimensional finite element numerical simulation and analysis of solid-state processing of metal material. Complexity. 2020; https://doi.org/10.1155/2020/8819745

[19] Kocańda A. Określenie trwałości narzędzia w obróbce plastycznej metali/Estimation of tool life in metal forming. Informatyka w Technologii Metali. Wydawnictwo Politechniki Śląskiej; 2003. pp. 213-256.

[20] Hawryluk M, Jakubik J. Analysis of forging defects for selected industrial die forging processes. Eng Fail Anal. 2016;58:396-409.

[21] Gronostajski Z, Hawryluk M, Kaszuba M, Zwierzchowski M. Analysis of forging process of constant velocity joint body. Steel Res Int. 2008;1:547-54.

[22] Krishna RH, Jena DP. Analytical and numerical modelling of open-die forging process for elliptical crosssection of billet. Measurement. 2019;134:855-65.

[23] Xu Y, Zhang Y, Zhuang X, Cao Z, Lu Y, Zhao Z. Numerical modeling and anvil design of high-speed forging process for railway axles. Int J Mater Form. 2020; https://doi.org/10.1007/s12289-020-01590-9

[24] Janjic M, Vukcevic M, Jurkovic Z, Sibalic N, Savicevic $S$. Physical modelling and numerical finite element method (FEM) simulation of forging in open die of alloy AIMgSi0,5. Metalurgija. 2016;55(2):181-4.

[25] Sheljaskow S. Tool lubricating systems in warm forging. J Mater Process Technol. 2001;113(1-3):16-21.

[26] Hawryluk M, Ziemba J. Lubrication in hot die forging processes. Proc Inst Mech Eng Part J. 2019;233(5):66375.

[27] Ellinghauden T. The revolution of simulation software development. Forg Magazine. 2013;6:16-8.

[28] Kopernik M, Milenin A. Numerical modeling of substrate effect on determination of elastic and plastic properties of TiN nanocoating in nanoindentation tests. Arch Civil Mech Eng. 2015;14(2):266-77.

[29] Lee SR, Lee YK, Park CH, Yang DY. A new method of preform design in hot forging by using electric field theory. Int J Mech Sci. 2002;44(4):773-92.

[30] Sedighi M, Tokmechi S. A new approach to preform design in forging process of complex parts. J Mater Process Technol. 2008;97(1-3):314-24. 
[31] Altan T. Cold and hot forging fundamentals and applications. Ohio, USA: ASM International; 2005.

[32] Lange K, Cser L. Tool life and tool quality in bulk metal forming. Proc Inst Mech Eng Part B. 1993;207:223-39.

[33] Lee SK, Ko DC, Kim BM. Optimal die profile design for uniform microstructure in hot extrusion product. Int J Mach Tools Manuf. 2000;40(10):1457-78.

[34] Forge NxT 2011, Documentation, Subsidiary Transvalor, E-Golf Park, 950 Av. Roumanille, 06410 Biot, France, https://www.transvalor.com/en/forge.

[35] Simufact forming reference, Simufact engineering. GmbH, Tempowerkring 1921079 Hamburg, Germany, https://www.simufact.com/.

[36] Gform. Hot forging, Application. 2021. https://www.qform3d.com/processes/hot. Accessed 11 Apr 2021.

[37] Venet G, Baudouin C, Pondaven C, Bigot R, Balan T. Parameter identification of $42 \mathrm{CrMo} 4$ steel hot forging plastic flowbehaviour using industrial upsetting presses and finiteelement simulations. Int J Mater Form. 2021; https://doi.org/10.1007/s12289-020-01609-1.

[38] Nytra M, Kubik P, Petruska J, Sebek F. A fully coupled thermomechanical damage analysisof hot closed die forging using finite element modelling. J Mater Eng Perform. 2020;29(12):8236-46.

[39] Xu Y, Zhang Y, Zhuang X, Cao Z, Lu Y, Zhao Z. Numerical modeling and anvil design of high-speed forg- ing processfor railway axles. Int J Mater Form. 2020; https://doi.org/10.1007/s12289-020-01590-9

[40] Bouissaa Y, Bohloolia N, Shahriari D, Champliaud H, Morin JB, Jahazi M. FEM modeling and experimental validation of quench-induced distortions of large size steel forgings. J Manuf Process. 2020;58:592-605.

[41] Hawryluk M, Widomski P, Kaszuba M, Krawczyk J. Development of new preheating methods for hot forging tools based on industrial case studies and numerical modeling. Metal Mater Trans A. 2020:51(9):4753-64.

[42] Marek H, Jacek Z, Lukasz D, Pawel K, Marcin K. Wear analysis of forging tools used in the hot forging processes using 3D reverse scanning techniques and cooling-lubricating system. Int J Adv Manuf Technol. 2018;97(5-8):2009-18.

[43] Dworzak Ł, Hawryluk M, Janik M. The impact of the lubricant dose on the reduction of wear dies used in the forging process of the valve forging. Materials. 2021;14(1):212.

[44] Hawryluk M, Ziemba J. Lubrication in hot die forging processes. Proc Inst Mech Eng Part J. 2019;233(5):66375. 